\title{
INDÍGENAS E NEGROS NAS CIDADES: ESCUTA CLÍNICA PARA A SAÚDE MENTAL E CIÊNCIA PSICOLÓGICA
}

\author{
Regina Marques de Souza Oliveira ${ }^{1}$
}

Resumo: As cidades do Recôncavo da Bahia possuem mais de $70 \%$ de populações negras. $\mathrm{O}$ indígena nestas cidades é presente por sua etnicidade orgânica: costumes alimentares, formas de viver, cultura e tradições religiosas no contexto a partir das manifestações populares. No Mato Grosso, os indígenas são quase 3,98\% da população enquanto que os negros são $65 \%$ do estado. As cidades negras e indígenas destes territórios são encharcadas da ancestralidade africana e da ancestralidade indígena. Com características marcantes eles constroem pensamentos nas ciências. Nas cidades estes corpos ecoam, transformando a vida de si e de todos. Aprender com seus legados é obrigação e débito a ser saldado, pelas ciências da saúde e psicologia.

Palavras chaves: saúde mental, indígenas, relações raciais, cidades, psicologia.

\section{INDIGENOUS AND BLACK IN CITIES: CLINICAL LISTENING TO MENTAL HEALTH AND PSYCHOLOGICAL SCIENCE}

Abstract: The cities of Recôncavo da Bahia have more than $70 \%$ of black populations. The indigenous people in these cities are present for their organic ethnicity: food customs, ways of living, culture and religious traditions in the context from the popular manifestations. In Mato Grosso, indigenous people make up almost 3.98\% of the population while blacks are $65 \%$ of the state. The black and indigenous cities of these territories are drenched in African ancestry and indigenous ancestry. With remarkable characteristics they build thoughts in the sciences. In cities these bodies echo, transforming the lives of themselves and everyone. Learning from your legacies is an obligation and debt to be paid, by the health sciences and psychology.

Keywords: mental health, indigenous people, race relations, cities, psychology.

\section{INDÍGENAS Y NEGRAS EN LAS CIUDADES: ESCUCHA CLÍNICA DE SALUD MENTAL Y CIENCIAS PSICOLÓGICAS}

\footnotetext{
${ }^{1}$ Professora do Centro de Ciências da Saúde, UFRB. E-mail: marquesregina@uol.com.br ; ORCID: https://orcid.org/0000-0003-3720-0922
} 
Resumen: Las ciudades de Recôncavo da Bahia tienen más del 70\% de población negra. Los indígenas de estas ciudades están presentes por su etnia orgánica: costumbres alimentarias, modos de vida, cultura y tradiciones religiosas en el contexto de las manifestaciones populares. En Mato Grosso, los indígenas representan casi el $3.98 \%$ de la población, mientras que los negros son el $65 \%$ del estado. Las ciudades negras e indígenas de estos territorios están empapadas de ascendencia africana e indígena. Con características notables construyen pensamientos en las ciencias. En las ciudades estos cuerpos resuenan transformando la vida de ellos mismos y de todos. Aprender de sus legados es una obligación y una deuda que deben pagar las ciencias de la salud y la psicología.

Palabras clave: salud mental, indígenas, relaciones raciales, ciudades, psicología.

\section{LES AUTOCHTONES ET LES NOIRS DANS LES VILLES: ÉCOUTE CLINIQUE DE LA SANTÉ MENTALE ET DES SCIENCES PSYCHOLOGIQUES}

Résumé: Les villes de Recôncavo da Bahia comptent plus de $70 \%$ de populations noires. Les peuples indigènes de ces villes sont présents pour leur ethnicité organique: coutumes alimentaires, modes de vie, culture et traditions religieuses dans le contexte des manifestations populaires. Dans le Mato Grosso, les autochtones représentent près de $3,98 \%$ de la population tandis que les noirs représentent $65 \%$ de l'État. Les villes noires et indigènes de ces territoires sont imprégnées d'ascendance africaine et indigène. Avec des caractéristiques remarquables, ils construisent des pensées dans les sciences. Dans les villes, ces corps résonnent, transformant leur vie et celle de chacun. Apprendre de votre héritage est une obligation et une dette à payer par les sciences de la santé et la psychologie.

Mots clés: santé mentale, peuples autochtones, relations raciales, villes, psychologie.

As cidades do Recôncavo da Bahia são formadas majoritariamente por mais de $70 \%$ de populações negras. E antes da ocupação portuguesa e presença dos africanos escravizados no Brasil, eram os indígenas a população majoritária no território até o surgimento das primeiras cidades brasileiras.

A Bahia, conforme o mapa dos territórios e zonas de quilombos da SEPROMI Secretaria Promoção da Igualdade Racial, é o estado de maior concentração de quilombos. O grande contingente encontra-se na região do Recôncavo da Bahia, estendendo-se ao longo da faixa litorânea em toda a costa baiana até o sul. Há também a forte presença de territórios quilombolas no interior do estado (SEPROMI, 2012). Além disso, a Fundação Palmares mapeou a cartografia dos quilombos no Brasil, e demonstrou que ela é vigorosa e plena desde antes da abolição da escravatura. Este fato que nos habilita considerar que a Lei Áurea foi apenas um instrumento legal que 
ratificou o que de fato já acontecia: as lutas por liberdade e igualdade, protagonizada por negros alforriados e quilombolas, era forte e insurgente no território brasileiro (PEREIRA, 2019).

Podemos interpretar a história a partir do fato de que os movimentos quilombolas há anos no território brasileiro faziam-se cada vez mais arrojados e insurgentes, fazendo crer - e temer - a iminência de uma Republica Negra liderada por Palmares. Muito embora na historiografia oficial as datas da queda de Palmares seja anterior ao advento da abolição formal, não podemos nos esquecer que se hoje os quilombos, com todo o esgarçamento social que vivem, resistem e ameaçam e são empecilho ao poderio de interesses do capital privado, anteriormente não era diferente.

Deste modo consideramos que a Monarquia fazia a leitura das lutas e exigências da resistência quilombola e esta consciência dos fatos, favoreceu que a princesa regente assinasse a legislação da abolição da escravatura em 1988. No entanto, o que se temia, em nossa interpretação histórica, viria apenas um ano mais tarde: com o golpe do militar Marechal Deodoro da Fonseca, institui-se a Republica.

No Estado de Mato Grosso a população indígena corresponde a 5,26\% de toda população indígena no país (Longsdon, 2014). Este contexto de organização das cidades brasileiras a partir do cruel genocídio da população indígena impacta também no extermínio virulento pela escravização do negro africano. Estes fatos são fundamentais de consideração para as ciências da saúde mental e para a psicologia.

Pensar em cidades, urbanismo e diáspora negra, nos insta a considerar a importância destes estudos para a compreensão da saúde mental da população brasileira indígena e negra, sem desconsiderar os brancos pobres, tendo por certo que o significado do protesto negro é a luta comum por igualdade. As lutas dos quilombos atestam isto.

As cidades brasileiras, assim como as grandes cidades do mundo, se organizam pela luta por sobrevivência. O movimento dos corpos, o trabalho, que institui as trocas comerciais, a organização e uso do espaço público e privado, o acesso a bens de consumo e necessidades básicas da vida.

As condições materiais, as violências físicas e vulnerabilidades objetivas existentes e expandidas no solo das cidades, inscrevem também sofrimentos e angustias. A vida, em sua precariedade, revela a fragilidade dos seres humanos em sua luta 
cotidiana pela sobrevivência, e as desigualdades na cidade é reveladora da impossibilidade ou insuficiente medida de bem-estar e desenvolvimento.

Nesta perspectiva, discutiremos como as configurações das cidades brasileiras permitem avançar no conceito de saúde mental, psiquismo e bem-estar emocional a partir da presença indígena e negra de algumas urbes brasileiras do Nordeste e Centro Oeste do país. Traremos no texto, elementos importantes para o desenvolvimento epistemológico do campo das ciências da saúde mental e da psicologia.

Enquanto ciências e práticas de cuidados em saúde, é importante o avanço na modalidade clínica de escuta de sujeitos - corpos - literalmente desprezados no constitutivo do desenvolvimento tecno cientifico.

Corpos negros e indígenas - físicos e psíquicos - não são apenas objetos investigativos como ocorreu no contexto mundial e brasileiro entre os séculos XV e XIX até os nossos dias. No cenário mundial o final do século XIX e todo o século XX será emblemático neste tipo de abordagem e a inscrição do tema será protagonizado também por grandes estudiosos negros e da diáspora africana, como Frantz Fanon, Du Bois, Abdias do Nascimento, Angela Davis, James Baldwin e lideranças políticas como Rosa Parker, Martin Luther King e Nelson Mandela, dentre outros.

No Brasil, no início do século XX, Juliano Moreira, um médico psiquiatra negro nascido na cidade de Salvador na Bahia, contestará as teses racialistas de Raimundo Nina Rodrigues.

Juliano Moreira, filho de Galdina Joaquina do Amaral, trabalhadora doméstica na casa do Barão de Itapuã, criou Juliano sozinha. O barão foi seu padrinho. Muito pobre, Juliano foi incentivado pelo barão, que também era médico e professor na Faculdade de Medicina da Bahia, a se tornar médico em função de sua inteligência brilhante. Formado, Juliano será reconhecido como referência em saúde nas cidades brasileiras e internacionais como em Paris e Lisboa por seus estudos sobre a sífilis, sua tese de graduação. No contexto de cidades europeias na Alemanha, Inglaterra, Bélgica, Holanda, Itália, Áustria e Suíça, o médico de etnia negra contribuiu com avanços importantes no entendimento sobre a doença e seus escritos serão citados em inúmeros periódicos científicos internacionais (HERÓIS DA BAHIA).

Ele também é pioneiro no campo da psiquiatria moderna no Brasil e era professor de clínica psiquiátrica e moléstias nervosas na Faculdade de Medicina da Bahia e há dez 
anos antes de qualquer outro, ele citava Freud em suas palestras e conferências, sendo um precursor da psicanalise no Brasil. Foi considerado louco por abolir as grades das janelas e a camisa de força no Hospital Nacional dos Alienados no Rio de Janeiro. Inovou promovendo a profilaxia da saúde mental, favorecendo a criação de legislações de assistência aos adoecidos mentalmente, dentre outras ações específicas do campo médico. Juliano não apenas se limitava em contribuir com os avanços clínicos nas ciências, ao contrário, incluía a isto a contribuição engajada por seu discurso social no combate à crença do racismo científico da psiquiatria brasileira no início do século XX. Era crítico de Raimundo Nina Rodrigues que afirmava a inferioridade intelectual das populações negras e combatia a ideia de que os adoecimentos psíquicos eram fruto da miscigenação (NEXO JORNAL).

A contestação sobre a inferioridade intelectual do negro, posição defendida por Nina Rodrigues, foi fato marcante na obra de Juliano, pois a minoria entre os médicos apoiava sua posição. Ele divergia e polemizava diretamente com o também médico maranhense. Pois Rodrigues afirmava que a degeneração do povo brasileiro era devido à mestiçagem com os negros (...) . Juliano Moreira, em oposição a Nina Rodrigues, defendia que na luta contra as degenerações nervosas e mentais, os inimigos a combater, não eram os negros, considerados inferiores na intelectualidade pela maioria dos médicos, mas sim uma ciência que se ocupasse de estudos sobre o "alcoolismo, a sífilis, as verminoses, as condições sanitárias e educacionais adversas; o trabalho de higienização mental dos povos, disse ele, não deveria ser afetado por "ridículos preconceitos de cores ou castas (...) (ODA \& DALGALARRONDO, 2000, p.178).

Dos alicerces importantes no campo da saúde mental e clínica psicológica Juliano Moreira é entre psicólogos e estudiosos do campo médico na saúde mental pouco conhecido. Fanon, também médico psiquiatra e negro, também é desconhecido por estudiosos do campo da saúde. O caso de Fanon é interessante porque sendo uma liderança médica e intelectual reconhecida no contexto emergente da ciência europeia, contemporâneo e respeitado por Sartre, Lacan, Mannoni, intelectuais da psicanálise e da filosofia humanista-existencial fenomenológica, ele será traduzido em vários países do mundo. Nas universidades americanas de medicina e principalmente nas ciências sociais, será um ícone dos estudos sociológicos dos mais importantes centros de 
pesquisa desse país (MACEY, 2011). No entanto, na própria França - em Paris - Fanon não é abordado nas grandes escolas doutorais parisienses.

Isto requer observar que nas cidades mundiais Juliano Moreira e Frantz Fanon, médicos psiquiatras atuantes em questões inovadoras nas urbes em que viveram e transitaram tiveram atuações importantes como sanitaristas no contexto das cidades do Brasil e do mundo. Igualmente, Virginia Leone Bicudo, como primeira psicanalista brasileira, era mulher e negra, filha de um negro nascido na lei do ventre livre (DAMACENO, 2017; OLIVEIRA, 2019) Bicudo, assim como Fanon e Juliano Moreira, inovaram nas cidades do mundo, a importância da observação dos contextos sociais, culturais e políticos para a saúde mental.

Juliano Moreira, em Salvador, no Rio Janeiro e no mundo, Frantz Fanon em Paris, Lyon e também no mundo, Virginia em São Paulo, em Brasília, em Londres (igualmente nas cidades do mundo), são alguns das muitas personalidades negras que inovaram no campo das ciências e da saúde mental, que nos ensinaram uma escuta clinica diferenciada para avanços no campo emocional e afetivo.

Seus legados e ancestralidades são fundamentos e alicerces importantes para a produção de ciências nas cidades do Brasil e do mundo. Foi no solo das grandes cidades urbanas, cosmopolitas e diversas de elementos humanos, que estes três desenvolveram seus trabalhos e ensinamentos. Escuta-los hoje, é obrigação da elevação do pensamento.

A partir de fragmentos de estudos sobre a população negra no Recôncavo da Bahia e em comunidades de cidades do estado do Mato Grosso, faremos a composição de um enredo que privilegie as marcas psíquicas do povo preto e indígena no percurso das cidades.

Tentaremos focalizar os corpos psíquicos da população negra e indígena nas cidades brasileiras. Observando a lógica de seus corpos no uso do lugar e do espaço. As formas civilizatórias de seu protagonismo no solo e territorialidade do urbano e como estes corpos se inscrevem a despeito das violências que os atravessam.

Procuraremos escutar as vozes que ecoam e cantam prodigiosas favorecendo a ampliação da consciência emocional sobre identidades, resistências, cosmovisões e vitorias apoteóticas que são existentes no solo destas cidades.

Nesta focalização da escuta psicológica do movimento dos corpos - físicos e psíquicos - de negros e indígenas, nas formas de manifestações destes corpos nas 
cidades, traçaremos as análises pertinentes a lógica emocional que fortalece as identidades processuais que se levantam - pois nunca estiveram prostradas, mudas ou ausentes - do jogo frenético de participação social e coletiva de pertencimento e uso gozo - dos espaços e territórios das cidades.

Ao realizar tal analise, optamos por um recorte psicológico, um fragmento, um breviário representativo do muito que é em si inapreensível. As vozes negras e indígenas que ecoam, para além do espaço e lugar das cidades onde estas vozes se encontram, são o ressoar de pássaros que em épocas de inverno e verão deslocam-se no continente rompendo fronteiras: atravessam o mar, vão além, não há lugar - a cidade é enorme e desproporcional a materialidade dos espaços. A cidade não é só a materialidade do espaço, mas o espaço é o todo: o indivíduo, o coletivo, a comunidade, a diáspora em seu deslocamento eterno e fixação presente nos milênios da oralidade - a cidade se faz corpo, físico e psíquico, e ao alcançar a oralidade materializada na voz dos vivos, encontra o eco dos mortos que são vivos na eternidade.

Por isso as cidades com a presença do povo preto e do povo indígena é mais amável, é mais rica, é mais alegre e tecnologicamente desenvolvida em humanidade.

O psiquismo e as necessidades de saúde mental humana atestam os benefícios das trocas simbólicas e materializadas entre os habitantes dos espaços nos locais das cidades.

Por tal medida começaremos por narrar os modos como a psicologia brasileira, profissão do cuidado e da saúde mental, começou por considerar a presença negra e indígena nas cidades - território - brasileiro.

Posteriormente, traremos as escutas - imagens "fotográficas e audiovisuais" - que registram, se fazem registrar, no psiquismo humano presente na clínica psicológica e psicanalítica. Fragmentos de analises contadas por pacientes que dividem a dor e a alegria da existência de corpos amalgamados pela presença negra e indígena, contrariando a lógica do eurocentrismo que tenta invisibilizar outros fatos, outras narrativas distintas das suas aparentemente legitimadas.

Ainda que assim pareça ser - a hegemonia eurocêntrica - não é o que narram os fatos psíquicos e mnêmicos das escutas mais bem posicionadas.

Ao observar e ouvir e dialogar com os fragmentos psíquicos e mnêmicos fortalecemos uma necessária, atual e contemporânea psicologia, a qual se inaugurada 
por corpos negros e indígenas que são capazes de escutar - dialogar - nos espaços acadêmicos de produção de psicologia com franca hegemonia branca e estruturalmente racista.

Para tanto, faremos um traçado histórico, como já dissemos, começando pelos primórdios da psicologia brasileira vinda de terras lusitanas.

\section{ESCUTA PSICOLÓGICA DO NEGRO E DO INDÍGENA NAS CIDADES: PRIMÓRDIOS}

A psicologia nas cidades e territórios brasileiros é originaria a partir de princípios eurocêntricos, vindos dos interesses dos colonizadores brancos portugueses. Assuntos como a "persuasão de selvagens", no caso os indígenas, eram os temas de investigação predominante. Assim como ideias sobre a inferioridade mental e intelectual das mulheres para a instrução. Os valores atribuídos a uma mulher índia e os atribuídos a uma mulher colonizada eram muito diferentes. Igualmente, propagava-se na "psicologia cientifica" a questão do "caráter do brasileiro", que, relacionado ao clima e ao ambiente, era considerado inclinado ao ócio e a dissimulação. O comportamento do brasileiro era determinado pela natureza que o "dispensava da luta", portanto o nativo e povos que aqui habitavam, a exceção dos brancos portugueses, eram tidos como preguiçosos, ociosos e propensos aos pecados (ANTUNES, 2015, p. 20).

Obviamente, se a escuta ao indígena a psicologia inaugural portou-se violentamente, querendo-os criados e mudos; com os africanos negros a violência foi também avassaladora.

A dependência do pensamento psicológico produzido no Brasil era voltado aos interesses da metrópole e a influência da Companhia de Jesus e da igreja católica favoreceu a concepção de uma interpretação racista da sociedade brasileira, atribuindo os problemas sociais e econômicos a questões raciais, pois os negros eram responsabilizados pelo atraso do país. Essas ideias desembocaram na defesa do "embranquecimento da raça brasileira" e, posteriormente, na busca da "pureza racial" (ANTUNES, 2015 p.50). 
Assim a psicologia no Brasil surge como produto de pensamentos racializados e posicionamentos eugênicos e eurocêntricos. Como considerar as inscrições psíquicas nos territórios urbanos e a presença negra indígena como o Recôncavo da Bahia?

\section{AS CIDADES DO RECÔNCAVO DA BAHIA}

Elas são formadas majoritariamente por mais de $70 \%$ de populações negras. O Recôncavo compreende uma região litorânea, banhada pela Baia de Todos os Santos, que em sendo atravessada faz ligação marítima com a cidade de Salvador.

A cidade de São Salvador, surge pela economia do Recôncavo. Após as inscrições dos indígenas nas terras brasileiras e na Baia de Todos os Santos, a força de trabalho humana dos africanos escravizados produziram as riquezas brasileiras através do cultivo de alimentos em larga escala, como a cana de açúcar, as frutas, o fumo, as hortaliças, enfim, uma agricultura forte, cujos produtos eram escoados pela Baia de Todos os Santos até Porto do Salvador, cidade de São Salvador.

Região rica economicamente em função da fertilidade de suas terras, além da tecnologia humana utilizada pelo colonialismo para otimizar as riquezas da colônia - o escravismo - a presença negra e indígena constituiu-se como elemento principal das etnicidades presentes nas cidades do Recôncavo da Bahia.

Podemos definir Recôncavo como a força da etnicidade indígena e negra, considerando que as cidades que nesta territorialidade se constituíram observam a inscrição de costumes e religiosidades negras e indígenas.

Os jovens indígenas e os africanos negros e povos da diáspora, definiram o apogeu econômico da organização das cidades do Recôncavo, através da produção agrícola e mão de obra na lavoura e pecuária.

Os rios que banham as cidades do Recôncavo e do litoral da Bahia são símbolos das águas para as populações indígenas e também negras. Ele é fundamental, pois proporciona o deslocamento fluvial, alimentação, subsistência física através do consumo das aguas nas nascentes e leitos dos rios que desembocam no mar. Os rios são os símbolos vivos da presença e hábitos indígenas nas cidades do Recôncavo, com o cultivo da culinária da pesca (mariscos, moquecas, pirão, siris e outros), e a vivência iintima com o barro, a cerâmica, os utensílios gerais do cotidiano indígena e negro. A 
lama nos manguezais e o cultivo do milho, do amendoim e da mandioca - aipim - e outros produtos importantes para a subsistência do indígena.

A população negra escravizada, simbolicamente tem nas aguas do Recôncavo das cidades da Baia de Todos os Santos, a intimidade com o Atlântico Negro, o deslocamento da diáspora, que colhe e deixa no leito das aguas dos grandes mares, as insígnias de seus pertencimentos. Suas vozes, seus cantos - canções - sua cosmovisão de existência e a recriação de seus símbolos humanos.

No curso das aguas da Baia de Todos os Santos, negros e indígenas fazem e refazem seus encontros civilizatórios na transformação e contribuição para o mundo. As aguas da baía, enquanto acidente geográfico, proporcionam a alteração das dimensões do mundo da vida para as populações humanas e inscrevem novos ciclos de pertencimentos e culturalismos advindos desta relação do indígena e do negro, atravessados pela violência branca europeia na formação das cidades do Recôncavo.

A Baía de Todos os Santos, com superfície de $1.233 \mathrm{~km} 2$, é o segundo maior acidente geográfico deste tipo no Brasil, com dimensão inferior à Baía de São Marcos, no Maranhão. Fazem ainda parte desse sistema duas outras baías de menores dimensões, respectivamente as de Iguape e Aratu, 56 ilhas, sendo a de Itaparica a maior ilha marítima do Brasil, estuários de rios, manguezais, restingas e matas que compõem seus ecossistemas e formam sua paisagem natural. Sobre estes substratos naturais foram construídos mais de cinco séculos de história, na qual as populações indígenas crescentemente perderam o protagonismo, desde o momento em que navegadores europeus aí aportaram (TAVARES, 2011, p.14).

Se existe a afirmação de que as populações indígenas perderam crescentemente seu protagonismo para o branco europeu desde o colonialismo; certo é que as inscrições indígenas e negras continuam presentes nos modos de fazer, sentir e viver das populações das cidades do Recôncavo da Bahia, bem como para as regiões litorâneas deste estado e as florestas e cerrados brasileiros no norte e centro oeste do país, a partir da região amazônica.

Esta língua e dialeto presente nos territórios destas cidades baianas e territórios brasileiros, no caso do Estado do Mato Grosso com grande percentual negro e indígena, representam as simbologias culturais e identidades de jovens e adolescentes habitantes destes territórios. Estados emocionais e psíquicos são componentes destas cidades e destas populações. 
A diáspora negra nas cidades do Recôncavo da Bahia e os indígenas nas cidades de territorialidades de etnias indígenas, estes povos, não se inscrevem enquanto exploradores do território no sentido material acumulativo ou de extração para a produção de riquezas. Eles se inscrevem enquanto força mnêmica, que relativiza a vida presente e os transcendem para a conexão com o passado de seus ancestrais e o lançam para as aberturas e possibilidades de encontro com o futuro.

A dimensão temporal entre passado, presente e futuro é harmônica e sincrética, pois corporifica, na psique do indígena e do negro africano e da diáspora, as simbologias de mundos civilizatórios, que dialogam com a existência humana para além de seu pertencimento objetivo de sua territorialidade geográfica.

No mesmo sentido, tal corporeidade mnêmica, alcança a dimensão física da relação com a paisagem e com o espaço - o tempo, que apesar de não plenamente cronológico e temporalizado, manifesta-se no fazer cotidiano dos corpos: comer, cantar, lavar, trabalhar, rezar, dormir, enfim, viver. E viver em relação com as crianças, os velhos a coletividade e a vida, que é natureza.

As cidades do Recôncavo terão ainda hoje, no século 21, economias comerciais pautadas na concepção de moralidade ética pela oralidade. Nos comércios das pequenas cidades do Recôncavo vários ainda são os estabelecimentos comerciais que se utilizam da nota promissória como moeda para a compra e venda de todo tipo de bens materiais.

Nas quitandas, nos grandes e pequenos mercados e nas frutarias, as cadernetas que registram os débitos dos clientes ainda persistem; e estes pagam, quando podem ou quando for a época dos acertos acordados oralmente.

Na economia das cidades do Recôncavo, persiste a letra do registro da oralidade, que permite que a palavra e a conduta sejam os códigos por excelência prevalentes e validados socialmente.

A moda, a roupa e os adereços das mulheres trazem o colorido dos panos, as penas e argolas nos brincos, a pouca roupa no calor, na exposição dos corpos que labutam a vida. Não é exposição erotizada e exibicionista, como pensam e violentam moralmente e fisicamente estes corpos (físicos e psíquicos), os brancos europeus.

É, ao contrário, a relação intima com a terra da Baia, com a lama do mangue e dos caminhos das restingas, a proximidade das águas e o inevitável encontro com o Sol. Com o calor e com o amor. Considerando amor, não como ato sexualizado pela 
sociedade patriarcal, branca, machista e capitalista. $\mathrm{O}$ amor para o indígena e o negro são atos de solidariedade e entrega à vida social comunitária: o cuidado com as crianças, o cuidado com as plantas e a observação com a natureza que faz parte da relação iintima com a vida. O corpo como elemento constitutivo desta natureza. Portanto pode ser despojado de vestimentas, ao menos em seus excessos.

Em projeto de extensão e intervenção em saúde com populações negras e quilombolas, os registros sobre os modos de considerar das populações atendidas foram organizados nos relatos clínicos e cadernos de campo de alguns estudantes (estagiários de psicologia, medicina e enfermagem) em atividade de supervisão (OLIVEIRA, 2019).

Vários serão os modos de dizer sobre as localizações geográficas nas cidades do Recôncavo para ensinar um caminho pelas populações negras e indígenas destas cidades:

Fica ali, na rua depois da igreja, segue em frente, subindo a colina, no horário que você vai chegar o sol está descendo então a luz estará baixa e você poderá ver o reflexo como se fosse um rio na direção de onde é o lugar. Ande um pouco mais e vire a rua, é bem em frente a um grande pé de cajá. Se você se perder, é só perguntar, onde é o pé de cajá...é fácil de achar

Ou então:

Segue reto, não tem errada. Haverá uma bifurcação e você segue acompanhando a direção das roseiras. Vai seguindo...vai passar um bom tempo...Se for rápido uns 20 minutos. Mais lento uma meia hora. Vai passar ponte de rio, riacho. Sobe morro. Come poeira. Nestes dias não tem chuva. Tá esta empoeirado. O outro pergunta: - Mas não tem endereço? Me passa o endereço! Ela continua: Espia só: Quando chegar perto você vai ver a igreja, desce morro, não mude a direção, depois de três coqueiros é o portão. Está aberto, é só empurrar.

A vida e os elementos da natureza estão imbricados. Não há descompasso nesta organização do cotidiano. A relação sujeito e natureza é de total intimidade. E os corpos transitam pela paisagem sem contradições extremas.

Se no transitar o espaço geográfico a cosmovisão é registro existente, também na comida os jeitos de fazer o dendê e temperar a moqueca trazem a relação do indígena com o negro. O peixe - a pesca - e a produção do óleo - os pés negros escravizados que "sambam" macerando o fruto do dendê, são registros de uma relação permanente com a vida, com o que é considerado importante para o deslindar da vida. O contato com as pessoas, os relacionamentos que promovem a vida, a direção do encontro: "o portão está aberto". 
No mesmo direcionamento são as organizações mentais dos jovens negros e indígenas no espaço urbano das cidades do Recôncavo e territórios citadinos dos povos das florestas.

Eles transmudam os registros inscritos na psique de seus antepassados ancestrais - que se presentificam no cotidiano de suas vidas - transformando-os em vozes emergentes.

O projeto colonialista que pretendia apagar a presença indígena do território do Recôncavo e das cidades aqui nascidas, não figurou-se vitorioso.

Os registros mnêmicos inscritos na psique dos sujeitos sociais negros, indígenas e jovens, estão evidentes. Estão vivos e permanecem marchando nos caminhos dos territórios das cidades. Contornando rios, adentrando florestas, superando colinas e mares.

A oralidade e a atemporalidade dos povos das florestas, negros e africanos incomoda os ocidentais. Porém ela tem um registro importante, e ao contrário do que pensa o Ocidente, ela é forte e permanente. Atravessa e vence as dores através do tempo. Superando inclusive o registro escrito, que é em si mesmo um recorte, um fragmento, uma restrição. Considerando que nem todo registro é possível de ser feito em uma folha de papel. Ou muitas delas que seja. Mas ao contrário, a palavra oral é transcendente. Atravessa os tempos. Se inscreve nos saberes das pessoas e permanece nas vozes daqueles que falam, pois antes eram a escuta das vozes de corpos que já se foram.

E se presentificam em vozes do agora: ancestralidade, é um signo da presença negra e indígena nas cidades do Recôncavo da Bahia.

E as vozes ecoam e registram-se na oralidade das mulheres, das mães. $\quad$ Elas foram as primeiras a entoar os cantos para salvaguardar a vida dos africanos que o mar, o Atlântico atravessavam. Elas sabiam que o poder de suas vozes milagrosamente possibilitava a permanência da vida, em condições insólitas. Elas sabiam que o canto negro de África era a ligação com o território de além mar, que havia ficado para trás, e ao cantar estes cantos, elas entoavam canções de ninar, capazes de fazer sonhar com a Terra Perdida, e a esperança de um novo mundo encontrar.

O cordão umbilical que liga homem e natureza à vida, se fazia presente no canto das mulheres africanas nos navios que atravessavam o mar. 
A cor dessa cidade sou eu

O canto dessa cidade é meu...

O gueto, a rua, a fé,

O toque do afoxé, ninguém explica

Ela é bonita...(Daniela Mercury)

O viver dos povos indígenas e negros são formados por cantos, mantras e orações que evocam para salvaguardar a vida que se apresenta diversa e forte em etnias, culturas e enredos de seus corpos em intima relação com a natureza.

Neste sentido podemos observar a baiana do acarajé nas cidades do Recôncavo. O sabor do camarão, bem como a origem do dendê macerado com os pés - da população das cidades rurais do Recôncavo - é marca da etnicidade negra e também indígena. A jurema - bebida preferida do índio "Caboclo Itapiranga", é servida também com o acarajé frito neste dendê - original - nas festas religiosas do Terreiros de Candomblé. A bebida jurema ${ }^{2}$ tem gosto semelhante ao sabor do canjinjin ${ }^{3}$ das festas do cerrado indigena brasileiro.

No centro-oeste brasileiro, em Vila Bela da Santíssima Trindade, primeira capital da cidade de Cuiabá, no Mato Grosso, o canjinjim é uma bebida à base de aguardente, mel de abelha, gengibre, cravo, canela, erva doce e raízes. O modo de preparo e outros ingredientes são transmitidos pela oralidade e contém segredos das populações negras e indígenas da cidade. A tradição é passada de geração à geração oralmente.

Em Cachoeira na Bahia, as Irmandades Negras e confrarias nasceram de um processo colonialista, mas com forte expressão das populações africanas que ali se localizaram. Do mesmo modo as Festas a São Sebastião na Comunidade de Bocaina na Baixada Cuiabana, com suas danças - siriri, rastreado, cururu - alimentos, bolo de arroz, moquecas, ensopados, músicas e instrumentos - viola de cocho, ganzá e cantos,

\footnotetext{
${ }^{2}$ Bebida feita a base de aguardente e especiarias para a Festa do Caboclo Itapiranga no Terreiro Yale Axé Yopondá Odé, no Alto do Morro no Recôncavo da Bahia, na cidade de Santo Antônio de Jesus.

${ }^{3}$ Bebida à base de aguardente com mel, canela, cravo e ingredientes "secretos", feita especialmente para a Festa do Congo de tradição negra e quilombola na cidade do Mato Grosso, Vila Bela da Santíssima Trindade, antiga capital do estado.
} 
são patrimônios imateriais tombados pela UNESCO e IPHAN (Instituto Patrimônio Histórico Nacional), respectivamente.

A comunidade de Bocaina, é uma comunidade onde as pessoas se ligam através da terra, é uma comunidade rural. A nossa comunidade, a gente se liga pela terra, mas também a gente se liga pela Festa de Santo que é a Festa de São Sebastião. Conversando com meus primos mais velhos que eu, o que nossos avos ensinam, a família toda se mobiliza pela Festa, que é uma louvação, um agradecimento a terra por dar o alimento e pelos animais estarem livres das pestes. Então a gente sente que isto está vivo entre nos. Apesar de muito dessa cuiabania se perde...que é o modo de fazer dos alimentos...que é uma especificidade daqui da Baixada Cuiabana, que é até tombada pelo patrimônio imaterial, que é o modo de fazer as coisas, o modo de fazer o bolo de arroz nosso, que é o bolo da minha tia, o bolo da "Tia Lola", que todo mundo conta: - olha, come bolo de arroz! Que é uma coisa daqui da Baixada Cuiabana, o modo de fazer a feijoada, a viola de cocho (...), o que nos temos aqui da Baixada Cuiabana que é o cururu, o siriri, o rastreado, a viola de cocho, que é um instrumento, uma viola com uma madeira especifica, feita de uma forma especifica, aqui da terra, também é tombada. Como patrimônio imaterial de Cuiabá. Faz parte de nossa cuiabania. Cantos tradicionais aprendidos de geração em geração, existem as famílias dos cururueiros... são convidados...as mulheres acompanham...é um ritmo, tem uma linguagem rápida. Sotaque cuiabano muito autêntico que as pessoas não compreendem... (Entrevista com estudante de história da UFMT, mulher negra, 22 anos) ${ }^{4}$

Conforme o relato da jovem, observamos que há uma linguagem especifica dos modos de ser e de fazer que é patrimônio imaterial das populações negras e indígenas da Comunidade de Bocaina. Existe uma linguagem, quase um dialeto, que pertence e se expande da ancestralidade para as gerações jovens e viventes que reatualizam, criam e recriam tradições que compõem as formas de produções subjetivas, narrativas e linguísticas das cidades. Estas composições são formadoras e formativas de interjogos afetivos e emocionais. Produções de sentidos psíquicos que servem de alicerces para a estruturação emocional dos sujeitos humanos e da vida social comunitária nas cidades, nos territórios locais e nas formas de sociabilidades para o enfrentamento e resistência do cotidiano de violências dos territórios sem cidadania a partir das imposições colonialistas cujo efeitos se reproduzem nas formas de sociabilidades do hoje - racismo institucionalizados, concentração de poder, desigualdades..., etc.

\footnotetext{
${ }^{4}$ Entrevista concedida pela estudante de história Tamara da Universidade Federal do Mato Grosso, campus Cuiabá, para documentário sobre saúde mental de populações negras e indígenas: contribuições da psicologia e da história.
} 
A etnicidade indígena e negra são presentes nos alicerces das cidades e do urbano. As cidades de economia rural e urbana edificam seu patrimônio humano a partir de pilares psicossociais e afetivos, nos quais os hábitos, os costumes, os modos de fazer, as ancestralidades e as transgeracionalidades atravessam as condições psíquicas dos sujeitos individuais, inserindo-os nos elementos tradicionais da cultura que alinha o pertencimento de um povo, meio e coletividade.

Nesta perspectiva, a condição emocional, o bem estar de si, enquanto sujeito individual, é dependente das condições e alicerces do passado em termos sociais, comunitários e coletivos. Estas pilastras que são recriadas em bases anteriores de um passado longínquo, produzem estruturas emocionais que possibilitam o sujeito estar bem posicionado emocionalmente e psiquicamente.

Os alimentos, danças, espiritualidade, pinturas e ritualísticas são reconhecimentos étnicos de identidades que se fragilizam nestes corpos que são presentes no território das cidades brasileiras em função de um estado nação que se formula a partir da negação da presença destes corpos, organizando extermínios tácitos para o genocídio das populações negras e indígenas.

Na umbanda, religiosidade negra indígena, o Caboclo Tupã, nos centros religiosos das cidades do Recôncavo, se apresenta nas festas nos moldes do comportamento ritualístico do candomblé; no qual mulheres e homens sentam-se em lados opostos do quadrante do terreiro a fim de que a tradição ancestral da diáspora negra se presentifique na cosmovisão dos participantes das manifestações religiosas. Há a cosmovisão de culturas distintas, indígenas e negras, que se apresentam comunitariamente; o Caboclo Tupã ou Índio Caboclo Itapiranga organizam seus ritos a partir de semelhanças com as tradições dos cultos indígenas ou dentro do próprio culto afro-brasileiro do candomblé.

O culto que é indígena torna-se também negro. E o culto que é negro diaspórico, torna-se também indígena ou afro-indígena. Em um amalgama que não apaga, mas ao contrário, fortifica, a potencialidade do vir a ser dos sujeitos individuais e coletivos, no empoderamento das tribos - as cidades - e as territorialidades periféricas (conhecimento de mundo, cosmovisões, processos civilizatórios) que engendram os mecanismos psíquicos das crianças, adolescentes e jovens.

Esta religiosidade, sem entrar em aspectos específicos e mais aprofundados, representa as formas do cotidiano das populações viventes nas cidades do Recôncavo da 
Bahia. E também como vimos no relato da jovem, o cotidiano e psiquismo das populações presentes nos territórios majoritariamente indígenas das cidades brasileiras, como na Baixada Cuiabana no Mato Grosso.

No nordeste, mulheres, crianças e homens, vivem entre a dimensão religiosa e a vida presente. Alicerçando seus passos a partir dos ensinamentos dos povos que fundam e habitam a Baia de Todos os Santos - os indígenas e os negros.

O elemento branco, o europeu, presente na configuração das cidades do Recôncavo, é aquele que contribui para trazer a violência, a exigência do massacre pela via do acumulo dos bens e apropriação das riquezas.

A Baia do Recôncavo é para o indígena - os caboclos - e também para os negros - africanos e da diáspora negra - o lugar de pertencimento étnico. Pautado no universo simbólico destes povos. O Rio que em seu curso encaminha-se para todos dos mares, o Oceano, a Natureza, a origem da vida.

Na mesma medida, a Baixada Cuiabana, na Festa de Santo - São Sebastião - é também para indígenas e negros. Pois sabemos que Oxóssi, no candomblé africano, é o caçador da floresta. Oxóssi é um indígena e caboclo da mata, que possui um arco e uma flecha.

A cuiabania mato-grossense elege na Comunidade da Bocaina a louvação à São Sebastião. E quem está por trás da figura de São Sebastião para os negros da diáspora e os indígenas do Brasil?

A colonização e o escravismo nos levou a colocar na frente Santa Barbara para proteger nosso culto a Iansã. Hoje, cada vez mais, temos a obrigação de ensinar que no candomblé isto não existe. Iansã é Iansã. Santa Barbara é Santa Barbara. Mas foi um processo importante para proteger nossos ancestrais e nossos cultos. Os santos católicos foram os protetores, os "anjos de guarda", que permitiram manter o culto aos Orixás. Esse momento passou. Precisamos agora ter consciência do valor de nossos ancestrais (Mãe Nilza da Oxum, 2011) ${ }^{5}$

O valor aos ancestrais significa cultuar a vida, a relação com a natureza, a pedra que encanta Orixá. Na mesma medida que para o indígena o culto a natureza é o seu grande sentido de vida e pertencimento civilizatório.

\footnotetext{
${ }^{5}$ Fala em Mini Curso de Mãe Nilza da Oxum do Terreiro Ylé Axé Yoponda Odé, no Alto do Morro, zona rural de Santo Antônio de Jesus no Recôncavo da Bahia, realizado em 2012 n o Fórum 20 de novembro na Universidade Federal do Recôncavo da Bahia.
} 
São Sebastião para o indígena e para o negro da diáspora nas cidades do Recôncavo da Bahia e da Baixada Cuiabana no Mato Grosso representam a resistência destes povos diante da violência do escravismo.

Foi impossível manter a existência nos preceitos civilizatórios explícitos diante da territorialidade forjada pelos brancos - europeus colonizadores - e toda geração e sentidos que precederam seus dogmas, barbáries e crueldades.

A violência dos brancos europeus tentou suprimir a existência de outros paradigmas civilizacionais no solo das cidades brasileiras como no Recôncavo e na Baixada Cuiabana no Mato Grosso, bem como em toda a territorialidade vilas e cidades de nosso país.

Sobreviver ao estrangulamento dos sentidos e da psique era fundamental para o povo preto e povo indígena. Sobreviver ao massacre e a violência física e psíquica premeditada era o mínimo possível. O máximo, era preservar a comunicação com a ancestralidade. Reunir forças para manter os ensinamentos vivos. Não se deixar esgarçar e destruir no sentido da linguagem e das narrativas. Construir uma cidade, territorialidades e fronteiras que pudessem ser demarcadas na psique negra e indígena. Relembrando do passado, da origem, do enraizamento e pertencimento ao lugar civilizatório dos povos pretos e dos povos indígenas. Religar -se ao ancestral, manter viva a tradição era e é o único caminho para a salvaguarda emocional da existência psíquica do sujeito.

Assim, a saúde mental pode ser estabelecida e restabelecida para estas populações, que a partir de sua própria epistemologia em saúde e psiquismo, consegue o antidoto para a violência do corpo e da emocionalidade negra e indígena. Da diáspora e dos povos pertencentes a terra brasileira, o antidoto e a cura para os brasileiros - indígenas, negros e brancos pobres.

Sob tal perspectiva, os processos civilizatórios do povo preto e povo indígena revelam a capacidade de elaborar tecnociência em saúde mental. A tecnologia destes povos e suas civilizações sempre foi altamente desenvolvida.

Nos arredores da cidade do Cairo, no Egito, as pirâmides construídas pela civilização africana, são um dos muitos exemplos das tecnologias matemáticas em engenharia e arquitetura dos povos africanos. A civilização do Nilo também é exemplo 
de grande processo de desenvolvimento tecnológico e evolutivo, na relação com a intimidade com a Natureza do Rio.

A conexão da vida com a morte era (é) para o povo africano (e também da diáspora) componentes do cotidiano. Se os egípcios, africanos que são, preparam e mumificavam o corpo com o melhor dos perfumes, roupas e joias para o encontro com seus deuses ancestrais; para os indígenas, o culto à Terra Mãe, o processo civilizatório é em direção semelhante. Não há contradição entre vida e morte, natureza e ser humano. Indivíduo e sociedade não são oposições. São composições. Ampliações presentes no conjunto da existência que representam o processo civilizatório destes povos.

Emocionalmente, saúde mental implica este tipo de arranjo harmonioso. As estruturas psíquicas - mentais - para as civilizações negras e indígenas estão alicerçadas na ancestralidade e na conexão da via com o ancestral que é o colo e significação cultural para a transmissão psíquica infantil. A ancestralidade negra e indígena tem na Mãe - a Terra Mãe - o surgimento da criança e da vida. O passado cria o presente e o futuro. E todas as cronologias - passado, presente e futuro, são atemporais. Não porque é inconsciente, como diria a psicanalise. Mas porque a ancestralidade e a saúde mental, se inscrevem a partir do colo materno, que possui uma significação cultural capaz de proteger a vida no ambiente social. Pois o psiquismo humano é formado pelas experiências emocionais e afetivas vividas na mais tenra infância da existência humana.

A mãe embala a criança em todo o "caldo" de seu pertencimento étnico e transmissão cultural presente em sua genealogia de pertencimento e filiação social e histórica (Oliveira, 2016, p.28). Esta ancestralidade e transmissão cultural esta impressa no chão das cidades, nas formas de comportamentos sociais entre os sujeitos no espaço habitado.

Por esta razão as demandas da clínica da saúde mental e do psiquismo humano na contemporaneidade precisam considerar as territorialidades de pertencimento do sujeito.

O conhecimento e observação dos corpos na diversidade do trânsito das cidades possibilita ao analista a expansão da consciência das formas de produção subjetiva dos seres humanos e os significados de seu sofrimento e/ou existência.

As cidades negras e indígenas do contexto brasileiro são retratadas a partir de visões que pouco observam os corpos negros, indígenas e "diferentes" do desenho comum do sentido clássico do que vem a ser a urbe em sua significação grego romana, 
o sentido da polis para os corpos masculinos e pertencentes a nobreza. Neste tipo de urbe, mulheres e escravizados não teriam acesso as decisões engendradas na polis grega, que poderia ser considerada uma das primeiras noções clássicas de urbe.

Nos relatos que apresentamos dos contextos das cidades indígenas do Mato Grosso e das cidades negras do Recôncavo da Bahia, é possível observar que a noção citadina é mais vasta no que concerne a possibilidade de pensar as configurações emocionais e psíquicas dos sujeitos humanos em seus processos civilizatórios. Neste sentido, a cidade é o corpo material do psiquismo, o local e espaço onde ele se representa e se reflete. Ganhando dimensões simbólicas internas, individuais subjetivas, imagéticas - mas também sociais, coletivas, comunitárias.

Os quadros narrados pelos enredos da Yalorixá, representações musicais da jovem pesquisadora da Comunidade de Bocaina, presença negra e indígena nas cidades brasileiras, o modo de falar e posicionar-se no contexto da cidade revelam a riqueza afetiva e emocional que o espaço e a paisagem da cidade organiza nos diferentes corpos que a compõe. A riqueza emocional não é gratuita. Ela pesa em sanidade mental, em bem estar emocional que promove fortalecimento psíquico e afasta vulnerabilidades físicas e mentais.

O acesso à cidade - a cidadania - é condição de saúde psicoemocional, saúde mental. O diálogo de ideias, de sonhos e ações compartilhadas nas cidades, permitem a existência plena do sujeito. As trocas entre os seres humanos são a garantia do bem estar emocional. Quando não há relacionamento, narrativas de vida, exercício da linguagem, a condição humana regride e o psiquismo tende a ficar embotado.

Compreender como as cidades acolhem os sujeitos pertencentes aos seus territórios é compreender o psiquismo humano. É estar preparado psicologicamente para compreender o sofrimento, os significados linguísticos e narrativos do sujeito em seu psiquismo, angustias, ansiedades e medos. Na mesma medida em que é possível em termos de intervenção em saúde, organizar medidas que correspondam a certa aproximação das realidades destes sujeitos em seus territórios, suas cidades.

As cidades devem refletir o empenho dos corpos e as vivências emocionais plenas, as narrativas e linguísticas do psiquismo da saúde mental e da psicologia. Ouvir e escutar estas vozes é técnica que precisa ser apreendida por psicólogos e profissionais da saúde mental. É preciso ser capaz de escutar e aprender com o movimento da 
etnicidade destes corpos no enredo das cidades, o território: o cultivo da terra, as manifestações artísticas, culturais, religiosas, a expressão do trabalho, o contato com a natureza e o calor dos corpos, o modo de fazer e aprender, o partilhar as ações dos dias em seus diferentes tempos cronológicos: nas manhãs, nas tardes e nas noites.

Como vimos, esta cronologia é atemporal para o corpo psíquico, embora ele se organize na temporalidade objetiva da cidade. Por isso é importante que a psicologia e a ciência da saúde mental conheça as narrativas dos elementos que compõem o interjogo dos sujeitos na cidade na busca por cidadania.

Cidadania, assim como psiquismo, são adventos civilizatórios. Representam o status da condição de desenvolvimento humano: acesso a saneamento básico, educação, lazer, saúde, habitação e trabalho. No mesmo sentido o psiquismo se estrutura, se conserva e se expande a partir da relação do ser humano com o espaço, com a natureza, a sociedade e os bens existentes no território (lugar) e no espaço.

Quanto maiores os desenvolvimentos da relação do homem com o lugar e o espaço, melhores poderão ser os desenvolvimentos psíquicos, os quais incluem a memória, a atenção, o raciocínio, a inteligência, enfim os produtos das emoções e aspectos subjetivos dos sujeitos. Note-se que aspectos e elementos subjetivos se organizam a partir de uma materialidade empírica, objetiva, factual. Portanto histórica, social, coletiva e comunitária e portanto, psicológica e dependente de sanidade mental.

A emocionalidade, a saúde mental e o entendimento sobre o desenvolvimento psíquico ocorre a partir da materialidade da existência humana. As cidades são os lugares da existência. São os locais e espaços onde os corpos se posicionam e exercem a vida. Sendo assim, os sentidos dos corpos físicos e psíquicos expressos nas ancestralidades, os relatos, as narrativas e os modos das identificações dos lugares trazem os significados da presença humana na cidade - presença indígena, presença negra na cidade.

Estes corpos, para além das narrativas orais, eles falam, eles transitam e espelham suas imagens no reflexo da conjuntura da cidade.

$\mathrm{O}$ direito a cidade é o direito que exercem. Não é um direito formal à cidade, que se converte em cidadania. 
Porém, as populações negras e indígenas, elas convergem para o uso do espaço, da paisagem e do lugar, expandindo suas fronteiras de ser e existir para além dos espaços cartográficos da cidadania da cidade que formalmente lhe é negada.

Assim sendo, mesmo negado-lhes o direito formal à cidade, à emocionalidade o psiquismo emergente de sua interpretação histórica da existência, confere-lhes a ousadia de transformar a paisagem da cidade, de produzir a lógica do conflito - porque em sendo conflito, em sendo tensão, é também, dialogo. Povo Preto e Povo Indígena fala. Permanece em existência, física e psíquica.

No espaço das cidades do Recôncavo e das cidades da Baixada Cuiabana, a Beira Rio, as expressões e exigências de diálogo - componente linguístico por excelência humano - se apresentam no bojo das necessidades dos povos pretos e indígenas.

Quem se adianta ao diálogo - signo por excelência civilizatório - é o povo preto. É o povo indígena.

A lança de Oxóssi reina, o caçador que vem da mata, da cidade de Aruanda. Ele, aproximando-se amavelmente de sua natureza, domesticou o cavalo. Vem montado em seu cavalo, cavaleiro da cidade de Aruanda.

A colheita farta e os animais livres da peste, como nos festejos de janeiro da Comunidade de Bocaina e comunidades Beira Rio no Pantanal de Mato Grosso, no canjinjin de Vila Bela da Santíssima Trindade (MT) ou na bebida jurema nos festejos do caboclo Itapiranga na cabana da Roça do Quilombo Alto do Morro no Recôncavo (BA); tudo se realiza porque a organização da cidade proveu o desenvolvimento dos humanos, povo preto e indígena, que celebra as bênçãos de uma territorialidade - espaço, lugar, cidade - que se integra e não rivaliza com a natureza, com o meio ambiente. Não rivaliza porque se concebe como parte integrante e pertencente, unida a este espaço.

Nesta cosmovisão que se organiza histórica e materialmente, o advento do psíquico se inscreve em pleno desenvolvimento, a saúde mental - quadros de depressão, ansiedades e pânicos talvez pudessem existir como facetas relevantes das incongruências inerentes aos desafios humanos frente o espaço e a integração com a natureza e as pessoas.

Problemas com certeza sempre irão existir: se Oxóssi traz a lança, ela serve para lutar, para caçar, para prover a vida. Mas a lança é instrumento do trabalho, da luta pela 
sobrevivência, e neste sentido, o psiquismo é também sempre guerra e paz. Luta e desenvolvimento. Conquistas e desafios.

Oxóssi é um grande guerreiro. É, na linguagem da civilização negra diaspórica no Brasil, o responsável pelo desenvolvimento e guardião provedor da humanidade.

Para o indígena não há contradição entre natureza e vida do cotidiano. A natureza é a vida humana e portanto deve ser reverenciada, cultuada e cuidada.

O cuidado com a vida é a preservação de si, da população e do planeta.

$\mathrm{Na}$ religiosidade negra africana, na diáspora, os ritos aos orixás podem ser traduzidos como iniciação a relação civilizatória entre ser humano e natureza.

Nas palavras de Mãe Estela de Oxóssi:

A nossa religião valoriza a natureza. O orixá é força vital e corresponde aos elementos da própria natureza que são: a Água, a Terra, o Fogo e o Ar. Para você ver como nós, principalmente quem cultua e quem pratica a religião dos orixás e que está mesmo entregue aos orixás, nós vemos o nosso corpo como um templo. Por quê?! Porque todos os seres são formados das partículas de cada um desses elementos que são a Terra, a Água, o Ar e o Fogo. Por isso temos conosco uma partícula de cada orixá infuso em nós mesmos. Isso independe da etnia, crença ou condição social, todos têm. A pessoa pode ter outra religião e nem por isso deixa de ter o corpo formado por esses elementos (Mãe Estela de Oxóssi, 2002, p.27)

A integração com a natureza é conceito de desenvolvimento psicológico e saúde mental. As falas da Yalorixá traduzem o bem estar emocional que a ciência psicológica deve buscar para desenvolver seu constructo epistemológico. É no chão da cidade e do território que a psique se desenha na etnicidade encarnada nos ritos e manifestações simbólicas de nosso povo, transfigurando imagens, pensamentos, visões civilizatórias que se organizam no cotidiano de crianças, jovens e adultos pertencentes a estas etnias do Brasil. O desenvolvimento tecnológico em saude mental e psicologia precisam considerar os ensinamentos destes povos em sua ampla visão tecno cientifica impressa em seu cotidiano. A música, enquanto arte e também terapêutica emocional é revelação psíquica:

"Okê Arô!!

Oxóssi é caçador

Ô Lua Branca Leruê

Ô Lua Branca Leruá

Quem é o cavaleiro que vem lá de Aruanda?

É Oxóssi em seu cavalo, com seu chapéu de banda.

Quem é esse cacique, glorioso e guerreiro, 
Vem montado em seu cavalo, descer no meu terreiro?

Ele é filho do verde, ele é filho da mata.

Sarava Nossa Senhora, a sua flecha mata!

Galo cantou tá chegando a hora

Oxalá tá te chamando

Caçador já vai embora!"’

Os elementos da canção nos deixa evidente o trânsito formativo da psique transgeracional e ancestral da população indígena e negra - diáspora africana - no Brasil.

Se Oxóssi é um orixá do candomblé, ele é também um índio, um guerreiro que tem arco e flecha. Ao mesmo tempo ele - Oxóssi - cultua e saúda a Lua, que é um culto especifico dos povos indígenas: Ô Lua Leruê! Ô Lua Leruá!

Índios e diáspora negra não podem ser considerados um só povo. No entanto eles estão imbricados nos modos de constituição subjetiva da vida e cotidiano das cidades do Recôncavo da Bahia e das regiões e territórios indígenas do Brasil.

Povo Preto e Povo Indígena se organizam em uma cosmovisão que se encaminha para o poder civilizatório da relação do ser humano com sua ancestralidade e o meio ambiente. Ser humano e natureza. Comunidade e individualidade, que se expande na condição de crescimento e evolução da espécie humana em seu conjunto - harmonia com a natureza.

As cidades tecnológicas aspiram esta necessidade evolutiva. E tecnologia é também preservação e harmonia com a natureza. É saúde em seu sentido amplo: física e mental.

O povo preto e o povo indígena são altamente desenvolvidos em termos de projeto civilizatório para uma cidadania plena. E seus ensinamentos empíricos de um ciência comprovada em seus modos de vida, devem ser aprendidas por psicólogos e pesquisadores do campo da saúde mental. Pois são epistemologias que possuem vastos conhecimentos necessários para a superação do sofrimento do ser humano na contemporaneidade.

Cidades ecologicamente organizadas, a partir da relação intima com o meio ambiente é a expressão da linguagem destes povos. Quando nos traduzem em sua cartografia o desenho da cidade no expressar da localização de seu lugar fisicamente e materialmente orientado no espaço, como nos foi apresentado nos relatos.

\footnotetext{
${ }^{6}$ Fragmento da canção Cavaleiro de Aruanda, de Tony Osanah. Álbum Tecnomacumba de Rita Benneditto, 2006.
} 
O bloqueio das fronteiras que compõem a diversidade das cidades, produz, por parte das populações não negras e não indígenas, a lógica de apropriação e extração desmedida da natureza. Isto impede que outras visões sobre o urbano ou o citadino se inscrevam no poderio das cidades capitalistas e liberais. Estas cidades, como se encontram, escravizam, subjugam e aniquilam populações mundiais - em geral povo preto e indígena - em prol de uma visão monossilábica e de pensamento único.

A diáspora negra nos legou Juliano Moreira, Franz Fanon e Virginia Bicudo, psiquiatras, socióloga e psicanalista, estudiosos da saúde mental e do psiquismo de populações humanas. Eles são alguns, existem muitos outros felizmente, dos cientistas negros da diáspora que nos fornecem importantes narrativas epistemológicas para a elevação civilizacional dos processos mentais e psíquicos das populações humanas.

Se eles encontraram forças para revolucionar as cidades e territórios em que pisaram, nasceram e transcenderam, é porque receberam por legado - transmissão psíquica e transgeracional - as vozes e cantos da diáspora, espalhados pelas cidades do mundo, criando novas cores e mosaicos de vida e encantamento.

Corpos negros que se levantam nas cidades - o Povo Preto e o Povo Indígena, transfigurado em seus elementos narrativos e linguísticos - portanto dialógicos - são o antidoto para a cura do sofrimento psíquico, da angustia e ansiedades desmedidas, dos processos depressivos, automutilações e tentativas de suicídio que assaltam a humanidade em nossos tempos.

Como o cavaleiro que é filho da Mata, ele cria as cidades com o poder da agricultura e da pecuária. A Festa de São Sebastião louva a vitória das necessidades humanas: a sede, a fome, a alegria, o encontro. $\mathrm{O}$ amor e a vida saudável em comunidade.

As narrativas linguísticas - corpo físico e psíquico - das populações negras e indígenas são cantos, diálogos, enredos, centrados nas ancestralidades; que nos dão provas de que a psicologia e a saúde mental protagonizada por estes povos, tem força, tem elementos, importantes a serem considerados, ouvidos, escutados, para uma ciência da saúde mental e psicologia que pretendam, assim como nossos ancestrais, romper as fronteiras da morte, em favor da vida.

Nas cidades, universidades brasileiras ainda cultivam a presença de uma psicologia e saúde mental que mantém os signos formativos a partir de um contexto 
branco europeu ou americanizado, ou seja, privilegiado e excludente (Oliveira, p.145, 2017).

Em cidades negras no Brasil e no mundo pisaram revolucionários cavaleiros negros e indígenas (Juliano Moreira, Frantz Fanon e muitos outros importantes da diáspora). Pisaram também inovadoras e ousadas amazonas da diáspora negra (Virginia Leone Bicudo e muitas outras) nas ciências da saúde mental e na psicologia.

Romper com uma psicologia que encarcera a vida e exalta a morte - a origem da psicologia brasileira com bases europeias, é seguir o signo de Oxóssi: o orixá negro e indígena da mata.

A força motriz destes corpos que marcham pelas cidades é a ancestralidade, movida pelo amor e compaixão pela humanidade. Suas vozes são audíveis. O amor nos narra - povos negros e indígenas povos. O chamado é antigo. Os ancestrais falam, pelos corpos que hoje vivem. Basta ouvi-los para avançarmos na produção de melhores sentidos físicos e mentais para a humanidade: o amor nos chama. Chegaremos lá!

Toté de Maianga: Caminhos de vida e de transformação nas cidades brasileiras e da disapora negra e indígena das matas dos mundos

Vinha passando pela mata escura

No bate folha ouvi uma canção

Que é pro santo poder sair da aldeia

Para chamar o Orixá dessa nação

Com o balanço do mar eu vim

Com o balanço do mar eu vou

E a enquisse que vovó me ensinou

Eu vou cantar que é pra chamar o meu amor

Chego lá, chego lá

Toté Toté de Maianga

Maiangôle $\hat{e}^{7}$

\section{REFERÊNCIAS BIBLIOGRÁFICAS}

ODA, Ana Maria Galdini Raimundo e DALGALARRONDO, Paulo. Juliano Moreira: um psiquiatra negro frente ao racismo cientifico. Memoria. Revista Brasileira de Psiquiatria. 22(4):178-9, 2000.

OLIVEIRA, Regina Marques de Souza. Cenários da saúde da população negra no Brasil. EDUFRB, Cruz das Almas, 2016.

\footnotetext{
${ }^{7}$ Canção Toté de Maianga de Gerônimo Santana. Um dos significados é caminho de vida e de transformação.
} 
OLIVIERA, Regina Marques de Souza. A formação do psicólogo nos contextos da diáspora africana. In: Oliveira, R.M (Org.) Dilemas da raça: empoderamento e resistência. Editora Alameda, São Paulo, 2017.

OLIVEIRA, Regina Marques de Souza. Currículo e Educação Quilombola no Recôncavo da Bahia. In: Psicologias, pedagogias e tecnologias em quilombos: conquistas e novos desafios. EDUFRB, 2019.

OLIVEIRA, Regina Marques de Souza. O canto das sereias: poéticas femininas negras na psicanalise brasileira. In: Pacheco, Claudia (Org.). Candace: Gênero, Raça, Cultura e Sociedade: construindo redes na diáspora africana. Eduneb, Salvador, 2019.

OLIVIERA, Regina Marques de Souza. Frantz Fanon, psicologia e psicanalise: epistemologia da violência. Revista ABPN, v.10, n.2, 2018.

OXOSSI, Mãe Estela de. Expressões de sabedoria: educação, vida e saberes. EDUFBA, Salvador, 2002.

TAVARES, Fatima. Baia de Todos os Santos - aspectos humanos. Editora da UFBA, Salvador, 2011.

Recebido em: 22/09/2020

Aceito em: 30/10/2020 